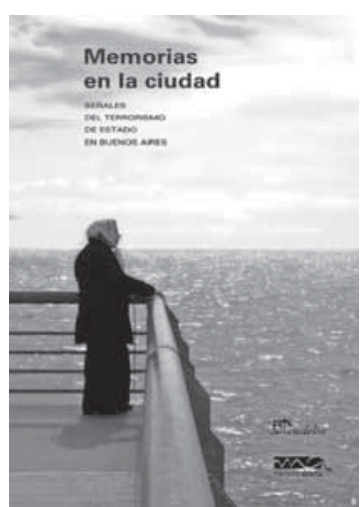

Ni guía ni ruta. Aunque casi no admite referencias negativas, "Memorias en la Ciudad" es un invento excepcional. No por nada el libro que reseñamos sugiere un uso alternativo de los recorridos por la Ciudad Autónoma de Buenos Aires en al menos dos sentidos. En primer lugar volviendo a destacar la historia muchas veces suprimida sobre cada uno de los sitios donde la última dictadura militar argentina condensó sus núcleos de diseminación del terror. $Y$ en segundo lugar, procurando que esos rincones se conviertan en ocasiones para el recuerdo. Presentado de este modo su diagrama, no es extraño que "Memorias en la Ciudad" arriesgue el intento por contribuir a la elaboración de la memoria en la sociedad, con el fin de influir en la cultura política y prevenirnos del autoritarismo en cualquiera de sus abyectas expresiones.

El trazado de estas consideraciones se funda en una idea central: para que la continuidad de la sociedad argentina pueda ser saludable, es conveniente que dentro de la esfera pública pueda situarse una apelación capaz de ejercitar y asegurar la permanencia del recuerdo de las personas represaliadas. Apelación que, desde un punto de vista contextual, requiere incluir el relato visual de las circunstancias que llevaron a que ello ocurriese. Tanto darle sentido como rescatar lo

\section{SeÑales del Terrorismo de Estado en Buenos Aires}

\author{
Memorias en la Ciudad
}

MEMORIA ABIERTA EUDEBA | BUENOS AIRES (2009)

ocurrido en sitios específicos de la ciudad son operaciones que contribuirían a motorizar procesos de reparación simbólica a las víctimas y a la sociedad en su conjunto.

Los autores organizan la publicación en nueve sectores, los que contienen dentro de sí a los distintos barrios que componen al territorio en cuestión: Montserrat, Puerto Madero, Retiro y San Nicolás; Palermo y Recoleta; Almagro, Balvanera, Boedo y San Cristóbal; Constitución, Barracas, La Boca, Parque Patricios, Nueva Pompeya y San Telmo; Belgrano, Coghlan, Colegiales, Núñez y Saavedra; Agronomía, Chacarita, Parque Chas, Paternal, Villa Crespo, Villa Pueyrredón, Villa Ortúzar y Villa Urquiza; Montecastro, Villa del Parque, Villa Devoto, Villa Gral. Mitre, Villa Real y Villa Santa Rita; Caballito, Flores, Floresta, Parque Chacabuco y Velez Sarsfield; Liniers, Mataderos, Parque Avellaneda, Versalles, Villa Lugano, Villa Luro, Villa Riachuelo y Villa Soldati. En cada uno de estos barrios se busca dar visibilidad a la amplia gama de dispositivos de memoria existentes en su territorio. Estas memorias se manifiestan bajo la forma de edificios, murales, placas conmemorativas, espacios públicos o escombros que cubren lo que allí ocurrió alguna vez. En algunos casos marcas evidentes, en otros como hebras recién 
hilvanadas, los lugares, como realidad y símbolo de lo que en ellos sucedió, son capaces de educar y motivar a la reflexión social.

A nuestro juicio tres son las características, propias de "Memorias en la Ciudad", sobre las que es posible estructurar un comentario. La primera se refiere a la metodología que aplica el relato sobre los lugares de memoria que destaca. El segundo punto se refiere a la cualidad pública que le otorga el libro a una memoria generalmente individualizada. Finalmente, la tercera y última característica se refiere al nuevo orden de interpretación urbana que sobre Buenos Aires dibuja el relato de Memoria Abierta.

Triple relato: testimonio, lugar e institución

En primer lugar, la forma en que los hechos son narrados y articulados en "Memorias en la Ciudad" contribuye a la función pedagógica de la lectura del pasado en clave presente. La narración de los sucesos se articula en base a tres fuentes de información: en cada uno de los casos confluyen testimonios, lugares e instituciones, bajo la forma de personas, espacios y procedimientos aplicados.

En la mayoría de las oportunidades, sea un sitio de operaciones dentro del sistema represivo de la dictadura o un lugar de homenaje y conmemoración -monumentos, esculturas, nombres de calles, nombres de salas y auditorios-, la aproximación al problema desde el lugar complejiza el análisis de las violaciones a los derechos humanos y de las políticas de memorialización de la sociedad argentina, sumando miradas y actores ayer invisibilizados.

El modo en que "Memorias en la Ciudad" plantea rescatar estos actos de memoria dentro de la ciudad se constituye como un acto de memoria en sí mismo. Por un lado, como sistematización de cientos de lugares y circunstancias asociadas a ellos. Al mismo tiempo, como penetración en múltiples historias y sentidos de la acción de los diversos agentes involucrados, ya sea como víctimas, victimarios, familiares de víctimas, "emprendedores de la memoria", autoridades del Estado o bonaerenses comunes.
A través de este enfoque, la investigación logra que el conflicto pueda ser entendido más allá de la básica distinción del nosotros/ellos al que recurren otros estudios, en los cuales prima el rescate de las voces militantes y los relatos heroicos de las experiencias políticas previas al golpe de Estado por sobre la comprensión profunda de la dictadura a partir de la variabilidad propia de su campo de actores.

La primacía del testimonio de las víctimas se ha instalado en el debate público de la dictadura, tanto en Argentina como en buena parte del resto de América Latina. Sin embargo, Memoria Abierta intenta con esta publicación dar un giro a esta tendencia, integrando en los testimonios tanto a los lugares como a los victimarios, lo mismo que a testigos indirectos y vecinos.

\section{Memoria pública}

Una segunda línea de análisis que presenta el libro se refiere a la capacidad de la memoria de insertarse tanto en el debate como en el espacio público. La tensión entre las memorias individuales y las públicas es resuelta, en el trabajo de Memoria Abierta, mediante la exposición y juicio de aquellas experiencias en las que los lugares de la memoria de la dictadura argentina se abren a lo público, al conocimiento y ejercicio del ciudadano común y corriente. Su trabajo se enmarca dentro del impulso que promueve Todorov (2000) por trascender de la memoria testimonial a la memoria ejemplar, en una búsqueda por superar la huella particular para construir socialmente una lección general.

Sin afectación ni grandilocuencia, el relato de "Memorias en la Ciudad" construye una memoria aparentemente dispersa, en la cual van entretejiéndose progresivamente centros de detención, lugares de tortura y sitios de conmemoración, con personas e instituciones. No por nada el título del libro habla de memorias y no de memoria, abriendo el abanico a la multiplicidad de sentidos que subyacen a las voces de la memoria dominante. Como era presumible en su diseño, la red polifónica de marcas en la ciudad permite una relectura de Buenos Aires que deja huellas sobre el imaginario urbano de sus habitantes. 
La hegemonía del testimonio, primer recurso de la memoria del dolor, se inscribe ahora en un marco urbano; lo que parecía borroso o extraviado en los testimonios, toma forma y adquiere lugar. En la medida en que el trabajo de Memoria Abierta avanza, los distintos sectores en que está divida la ciudad comienzan a entrelazarse ahora a través de una nueva capa de significación, a saber, la de la acción sistémica del terrorismo de Estado. Cada una de esas direcciones no es ya solamente parte de un barrio y una historia individual, sino que es parte de una red particular que marca tanto a Buenos Aires como a sus habitantes y visitantes.

De un modo siempre convergente, cada una de las crónicas de Memoria Abierta trasciende la esfera testimonial para encontrarse con la ciudad real, presente y pasada, como en el caso de Plaza de Mayo, el Colegio Nacional de Buenos Aires o el Hospital Militar, lugares que no se dejan circunscribir solamente por el período de la dictadura, sino que hacen parte de memoria variopinta y longeva que tiene tanto de agraz como de dulce. De esta forma la narrativa del libro penetra como un sutil hilo conductor en las profundidades de la memoria de los hechos previos al 24 de marzo de 1976, nos conduce a través de lo ocurrido entre ese año y 1983, y extiende su trayecto hasta el día de hoy. Así se logra tejer una red de correspondencia entre la ciudad de Buenos Aires y sus lugares de memoria. Estos sitios contienen la historia de la ciudad, y la investigación otorga una nueva profundidad a Buenos Aires mediante el develamiento de una red de recuerdos y significaciones que la atraviesa.

\section{Ciudad y museo}

En tercer y último lugar resulta de interés destacar la condición museográfica del libro. Más allá de su condición como guía turística de la ciudad, "Memorias en la Ciudad" permite reinterpretar a Buenos Aires como "museo de hecho" de la memoria de la dictadura y de la profundidad de la historia argentina.

Memoria e historia no son sinónimos (Nora, 2009). En el mejor de los casos la historia se constituye como consenso de las memorias en pugna. En el peor, la historia es escrita como verdad sin oposición. Una parte de la memoria colectiva se legitima oficialmente para convertirse en historia, en un movimiento en el que una parte de nuestros objetos cotidianos son convertidos en objetos de culto -confinándolos a los museos- y nuestras ciudades son reinterpretadas, por algunos, como parques temáticos.

En claro contraste, el trabajo de Memoria Abierta alienta una museografía de la ciudad de Buenos Aires que, en vez de encapsular el objeto a recordar, lo destaca dentro de su propio contexto. Es así como "Memorias en la Ciudad" se basa en la contextualización dispersa de los objetos del recuerdo en los lugares en que están circunscritos y en la profundidad temporal que los significa. Ese derramamiento, propio del funcionamiento del régimen, adquiere representación gráfica reflejándose en un mar de puntos que inundan el mapa de Buenos Aires que van uniéndose progresivamente, articulando la idea de la ciudad como escenario, museo y testigo de un sistema represivo.

Los testimonios, al lugarizarse, rompen con la idea de los sitios de la memoria como puntos aislados, para situarse al interior de la ciudad. En su acción centrada en el territorio, la investigación logra interpelar tanto a víctimas y victimarios como a visitantes, turistas y vecinos, en la medida en que amplía la condición de testigo a la de ciudadano. Este es probablemente uno de los mayores méritos de "Memorias en la Ciudad", e implica que lo que hoy se escribe para Buenos Aires pueda ser escrito mañana para Rosario, Montevideo, Barcelona, Sao Paulo, Concepción o Santiago, si se asume el desafío de entender la ciudad como soporte de la memoria colectiva. IEURE

\section{Referencias bibliográficas}

Nora, Pierre. (2009). Pierre Nora en Les Lieux de Memoir. LOM, Santiago.

Todorov, Tzvetan. (2000) Los abusos de la memoria. Paidós, Barcelona.

\section{Rodrigo Millán}

Sociólogo Pontificia Universidad Católica de Chile - Magíster en Desarrollo Urbano PUC.

\section{Valentina Rozas}

Licenciada en Arquitectura PUC. Magíster (c) Desarrollo Urbano pUC. 